\title{
Effects of Rich-Polyphenols Extract of Dendrobium loddigesii on Anti-Diabetic, Anti-Inflammatory, Anti-Oxidant, and Gut Microbiota Modulation in $\mathrm{db} / \mathrm{db}$ Mice
}

\author{
Xue-Wen Li ${ }^{1}$, Hui-Ping Chen ${ }^{1}$, Ying-Yan He ${ }^{1}$, Wei-Li Chen ${ }^{1}$, Jian-Wen Chen ${ }^{1}$, Lu Gao ${ }^{2}$, \\ Hai-Yan $\mathrm{Hu}^{1, *}$ and Jun Wang ${ }^{1, *}$ \\ 1 School of Pharmaceutical Sciences, Sun Yat-sen University, Guangzhou 510006, China; \\ lixw28@mail2.sysu.edu.cn (X.-W.L.); chenhp25@mail2.sysu.edu.cn (H.-P.C.); \\ heyingy2@mail2.sysu.edu.cn (Y.-Y.H.); wailap_1993@hotmail.com (W.-L.C.); cjw1975@263.net (J.-W.C.) \\ 2 BGI-Shenzhen, Shenzhen 518083, China; gaolu@bgi.com \\ * Correspondence: lsshhy@mail.sysu.edu.cn (H.-Y.H.); wjun@mail.sysu.edu.cn (J.W.); \\ Tel.: +86-203-933-6119 (H.-Y.H.); +86-203-994-3090 (J.W.)
}

Received: 11 November 2018; Accepted: 4 December 2018; Published: 7 December 2018

\begin{abstract}
Dendrobium is a traditional Chinese herb with anti-diabetic effects and has diverse bibenzyls as well as phenanthrenes. Little is known about Dendrobium polyphenols anti-diabetic activities, so, a rich-polyphenols extract of $D$. loddigesii (DJP) was used for treatment of diabetic $\mathrm{db} / \mathrm{db}$ mice; the serum biochemical index and tissue appearance were evaluated. In order to gain an insight into the anti-diabetic mechanism, the oxidative stress index, tumor necrosis factor- $\alpha$ (TNF- $\alpha$ ), interleukin- 6 (IL-6) and gut microbiota modulation were determined by ELISA, immunohistochemistry or high throughput sequencing $16 \mathrm{~S}$ rRNA gene. The results revealed that DJP had the effects to decrease the blood glucose, body weight, low density lipoprotein cholesterol (LDL-C) levels and increase insulin (INS) level in the mice. DJP improved the mice fatty liver and diabetic nephropathy. DJP showed the anti-oxidative abilities to reduce the malondialdehyde (MDA) level and increase the contents of superoxide dismutase (SOD), catalase (CAT) as well as glutathione (GSH). DJP exerted the anti-inflammatory effects of decreasing expression of IL- 6 and TNF- $\alpha$. After treatment of DJP, the intestinal flora balance of the mice was ameliorated, increasing Bacteroidetes to Firmicutes ratios as well as the relative abundance of Prevotella/Akkermansia and reducing the relative abundance of S24-7/Rikenella/Escherichia coli. The function's prediction of gut microbiota indicated that the microbial compositions involved carbohydrate metabolism or lipid metabolism were changed. This study revealed for the first time that DJP improves the mice symptoms of diabetes and complications, which might be due to the effects that DJP induced the decrease of inflammation as well as oxidative stress and improvement of intestinal flora balance.
\end{abstract}

Keywords: Dendrobium loddigesii; rich-polyphenols extract; db/db mice; type 2 diabetes mellitus; diabetes complication; inflammation; oxidative stress; gut microbiome

\section{Introduction}

Type 2 diabetes mellitus (T2DM) is a growing threat to public health. International Diabetes Federation estimated that in 2017 there were 451 million (age 18-99 years) people with diabetes worldwide, and the people with diabetes were expected to increase to 693 million by 2045 [1]. T2DM is a metabolism correlation disease; its main symptoms are hyperglycemia, insulin resistance, and decrease of insulin secretion. T2DM can cause death and disability because of various severe, whole-body complications in organs, such as, heart, kidneys, liver, brain, and others. 
The T2DM and complications etiology is complexity, many factors influencing their onset and development, such as, environmental and genetic factors. In recent years, oxidative stress and inflammation were recognized as one of the important causes of T2DM and complications [2]. Oxidative stress was considered as a unifying mechanism of diabetic and its complications [3]. Diabetes can lead to abnormal metabolism of energy, carbohydrates, fat and protein [4-6]; high glucose and free fatty acids levels can stimulate oxidative stress, increase the expression of inflammatory factors and lead to insulin resistance [7]. IL- 6 and TNF- $\alpha$, as major inflammatory factors, participate in the development of T2DM; the increasing expression of TNF- $\alpha$ and IL- 6 can cause pathological injury and diabetes complications $[8,9]$.

In recent years, gut microbiota was regarded as an important contributing factor in the occurrence and developing of T2DM [10,11]. The symbiosis of intestinal flora with humans is thought of as a "vital organ" of the human body, which can affect the host's energy metabolism; the studies of germ-free mice provided the evidence that the diversity or relative proportion of gut microbes played active roles in energy homeostasis [12]. The altered gut microbiota could affect inflammatory response as well as insulin resistance and play an important role in the development of T2DM [13]. Modulation of gut microbiota may become a novel therapeutic approach for T2DM [14].

"Shi-Hu" is a traditional Chinese medicine herb and from different species of Orchidaceae Dendrobium [15], which contains many compounds, such as polyphenols, polysaccharides, and alkaloids [16]. Dendrobium polyphenols are mainly bibenzyls, phenanthrenes, or their polymers [16]. Dendrobium polyphenols have diverse bioactivities $[17,18]$, such as, moscatilin, a dominant component of Dendrobium polyphenols, was reported to have antiplatelet aggregation, antimutagenicity, inducing apoptosis of cancer cells, and anti-inflammatory activity [19-22]; some polymers of bibenzyls or phenanthrenes showed inhibiting $\alpha$-glucosidase activity [23]. Dendrobium plants have been used to treat T2DM and complications in traditional Chinese medicine clinic $[24,25]$, such as, ethanol extract of $D$. chrysotoxum showed the abilities to ameliorates diabetic retinopathy [26]. D. loddigesii is one of the most important "Shi Hu" crude drugs in traditional Chinese medicine clinic, which contains abundant Dendrobium polyphenols besides polysaccharides and alkaloids $[27,28]$. In a previous study we found that the rich-polyphenols extract of $D$. loddigesii (Table S1) and its phenols components showed strong anti-inflammation and antioxidant activities in vitro [29]. To study anti-diabetic effects of Dendrobium polyphenols, a rich-polyphenols extract of D. loddigesii was prepared and its anti-diabetic effects, anti-oxidant, anti-inflammatory activities and modulation of gut microbiota were studied using $\mathrm{db} / \mathrm{db}$ mice.

\section{Results}

In Chinese medicine, prescript uses Dendrobium plants to treat T2DM and diabetes complications [24,30]. In order to explore the anti-diabetic effects of Dendrobium polyphenols, a rich-polyphenols extract (DJP) was prepared from $D$. loddigesii and used for treatment of diabetic $\mathrm{db} / \mathrm{db}$ mice (BKS.Cg-Dock7m +/+Leprdb/Nju) in 3 dosage groups, DMDJP25 group (in a dose of $25 \mathrm{mg} / \mathrm{kg}$ ), DMDJP50 group (in a dose of $50 \mathrm{mg} / \mathrm{kg}$ ), and DMDJP100 group (in a dose of $100 \mathrm{mg} / \mathrm{kg}$ ). BKS-Leprdb/Leprdb (BKS-db) mice are a widely used for T2DM animal models. Mice homozygous for the diabetes spontaneous mutation (Leprdb) manifest morbid obesity, hyperglycemia, diabetic nephropathy, steatohepatitis, and heart disease [31]. After treating 8 weeks, the effects of DJP on blood picture and organ histomorphology in the treated mice were observed and compared with no-treatment $\mathrm{db} / \mathrm{db}$ mice group (DM group), control group (C57 group), and metformin (MET) treatment group (DMMET130 group, in a dose of $130 \mathrm{mg} / \mathrm{kg}$ ) was used as a positive control group. To understand the anti-diabetic effect of DJP, the oxidative stress parameters, inflammatory factors, and modulation of gut microbiota were studied in the mice. 


\subsection{Main Compounds in DJP}

DJP is an enriched polyphenols fraction, from which about 21 phenols were identified using chromatographic techniques $[27,28]$. Under our analytical conditions only four components, moscatilin (1), gigantol (2), 2,4,7-trihydroxyl-9,10-dihydro-phenanthrene (3), and tristin (4) (Figure S1), were evaluated, which concentrations were $7.2 \%, 1.9 \%, 0.62 \%$, and $0.23 \%$, respectively.

\subsection{Anti-Diabetic Effects of DJP}

\subsubsection{Effects of DJP on the Body Weight, Blood Glucose Level, and Oral Glucose Tolerance (OGTT)}

The body weight and blood glucose level of the mice were tested once a week; the results were showed in Figure 1. OGTT was tested at the 7th week; the result was showed in Figure 2.

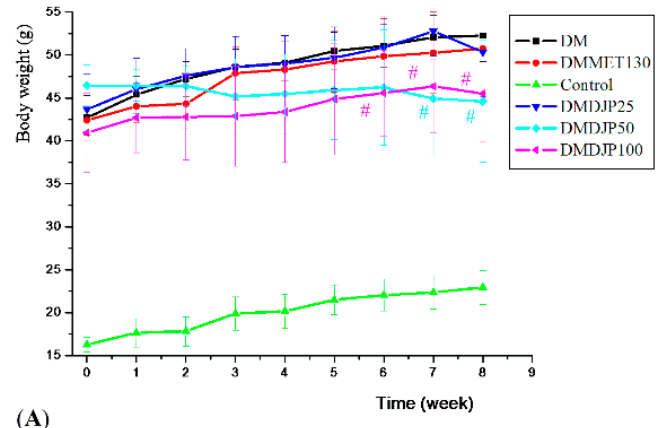

(A)

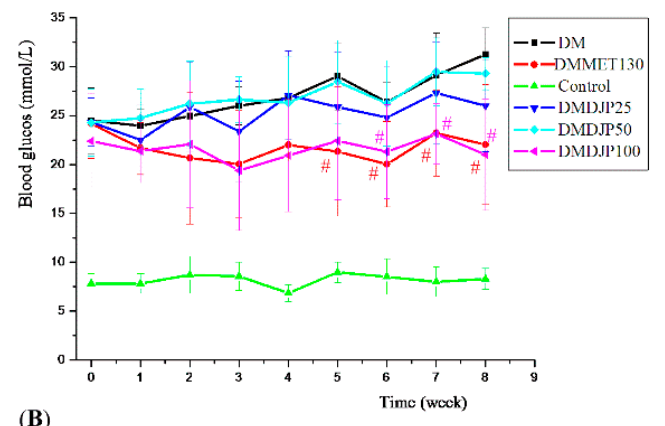

(B)

Figure 1. Effects of D. loddigesii (DJP) on body weight and blood glucose level across time in the mice. (A) Body weight changes over time; (B) Blood glucose level changes over time. Data are mean \pm SD; $\#=p<0.05$ vs. DM group.

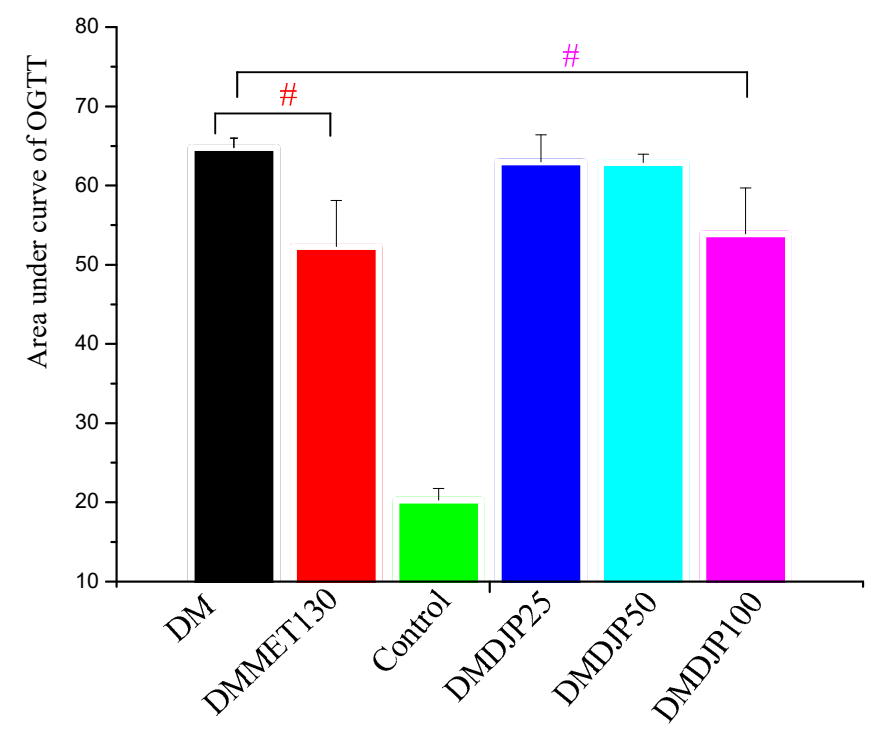

Figure 2. Effect of DJP on Oral Glucose Tolerance (OGTT). Data are mean \pm SD; $\#=p<0.05$ vs. DM group.

Figure $1 \mathrm{~A}$ showed that the body weight of $\mathrm{db} / \mathrm{db}$ mice was heavier than that of C57 control mice by $128-98.7 \%$. There was no obvious difference of the body weight among DM, DMDJP25, and DMMET130 groups. After 7 weeks of treatment, the body weight of DMDJP50 and DMDJP100 were significantly decreased by $15 \%$ and $13 \%$, respectively. ( $p<0.05$ vs. DM group).

Figure 1B showed that as DJP concentrations increases up to DMDJP100 the blood glucose level enhanced to $21.0 \mathrm{mmol} / \mathrm{L}$ compared to C57 control mice $(8.3 \mathrm{mmol} / \mathrm{L})$. Figure 2 displayed that the 
OGTT test in the $\mathrm{db} / \mathrm{db}$ mice indicated that all DJP concentrations mice showed higher OGTT areas than that of C57 control mice by enhancing blood glucose level by $120 \%$. However, the level of blood glucose and the OGTT test in $\mathrm{db} / \mathrm{db}$ mice were not affected with the concentrations of DMDJP25 and DMDJP50 tested. DMMET130 group enhanced the glucose tolerance level by $19.3 \%$ in OGTT test after 6 weeks of treatment $(p<0.05)$ compared to DM group. DMDJP100 group enhanced the glucose tolerance level in OGTT test ( $p<0.05 \mathrm{vs.} \mathrm{DM} \mathrm{group)} \mathrm{after} 6$ weeks of treatment, which was similarly to the effect induced by DMMET130 group.

\subsubsection{Effect of DJP on Serum Insulin and Lipid Levels}

The concentrations of triglyceride (TG), total cholesterol (TC), high density lipoprotein cholesterol (HDL-C), LDL-C, and INS in the mice serum were determined after the animal experiment; the results are shown in Table 1.

Table 1. Effects of D. loddigesii (DJP) on triglyceride (TG), total cholesterol (TC), high density lipoprotein cholesterol (HDL-C), low density lipoprotein cholesterol (LDL-C), and insulin (INS) levels in the mice serum.

\begin{tabular}{|c|c|c|c|c|c|}
\hline \multirow{2}{*}{ Group } & TG & TC & HDL-C & LDL-C & INS \\
\hline & \multicolumn{4}{|c|}{$\mathrm{mmol} / \mathrm{L}$} & $\mathrm{mIU} / \mathrm{L}$ \\
\hline DM & $1.45 \pm 0.21$ & $5.06 \pm 0.49$ & $0.99 \pm 0.18$ & $1.19 \pm 0.21$ & $7.06 \pm 1.63$ \\
\hline DMMET130 & $1.32 \pm 0.29$ & $4.69 \pm 0.59$ & $1.01 \pm 0.12$ & $1.20 \pm 0.12$ & $11.18 \pm 1.82^{\#, 1}$ \\
\hline Control & $1.01 \pm 0.27$ & $2.51 \pm 0.58$ & $1.10 \pm 0.21$ & $0.65 \pm 0.10$ & $10.64 \pm 3.74$ \\
\hline DMDJP25 & $1.50 \pm 0.31$ & $4.98 \pm 0.69$ & $0.93 \pm 0.12$ & $1.25 \pm 0.11$ & $8.22 \pm 3.80$ \\
\hline DMDJP50 & $1.48 \pm 0.19$ & $4.93 \pm 0.59$ & $0.96 \pm 0.19$ & $0.69 \pm 0.20^{\#}$ & $10.93 \pm 3.48^{\#}$ \\
\hline DMDJP100 & $1.49 \pm 0.33$ & $4.48 \pm 0.25$ & $1.03 \pm 0.12$ & $0.65 \pm 0.11^{\#}$ & $11.43 \pm 3.37^{\#}$ \\
\hline
\end{tabular}

Table 1 indicates that DMDJP25, DMDJP50, and DMDJP100 treatments of $\mathrm{db} / \mathrm{db}$ mice enhanced the concentration of TG in serum by approximately $1.50 \mathrm{mmol} / \mathrm{L}$ compared to control C57 mice $(1.01 \mathrm{mmol} / \mathrm{L})$. In addition, in the same experiments TG, TC, and HDL-C levels were not affected with different doses of DJP or MET (in $130 \mathrm{mg} / \mathrm{kg}$ dose). Further experiments in the same mice with DMDJP50 and DMDJP100, the level of LDL-C decreased than DM group $(p<0.05)$ by 0.69 and $0.65 \mathrm{mmol} / \mathrm{L}$, which were not decreased with DMDJP25 and DMMET130 treatment. Furthermore, the concentration of INS in DM group was lower by $7.06 \mathrm{mIU} / \mathrm{L}$ than control group or DJP treatment. Finally, the serum INS level in the $\mathrm{db} / \mathrm{db}$ mice treated with DMDJP50, DMDJP100, and DMMET130 increased by $10.93,11.47$, and $11.18 \mathrm{mIU} / \mathrm{L}$ than DM group $7.06 \mathrm{mIU} / \mathrm{L}(p<0.05)$.

\subsubsection{Effect of DJP on Tissue Forms of Liver/Kidney}

The changes of tissue forms of liver/kidney in the mice were observed by HE staining, and the results were showed in Figures 3 and 4, respectively; the result of pathological lesion analysis were displayed in Table 2.

The liver tissues in C57 control group showed normal morphology and a few lymph cell infiltrations were found occasionally. The liver tissues in DM group displayed severe hepatic steatosis accompanied by lymph cell infiltration. Compared with DM group, the hepatic steatosis in DMMET130 group was relieved (Figure 3B and Table 2). After 8 weeks of DJP treatment, the hepatic steatosis in DMDJP25 group was not improved, but the hepatic steatosis were significantly decreased in DMDJP50 group ( $p<0.05$ vs. DM group) and DMDJP100 group ( $p<0.01$ vs. DM group), which displayed certain dosage-effect relationship (Table 2). The lymph cell infiltration of liver disappeared in DMDJP100 group. 


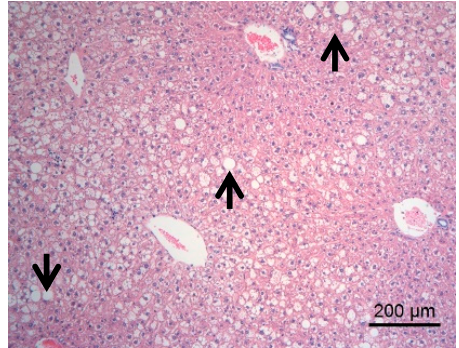

(A)

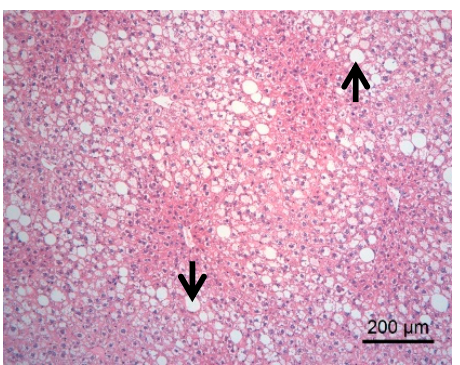

(D)

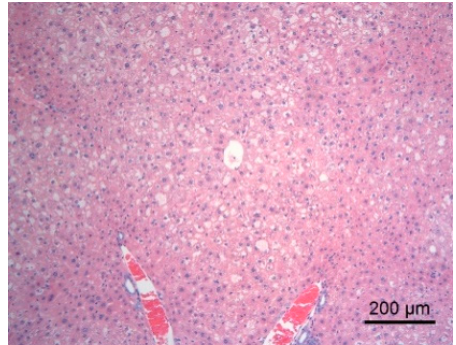

(B)

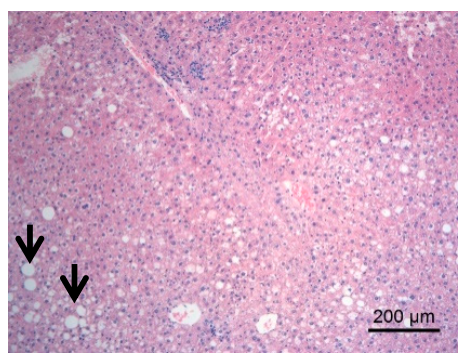

(E)

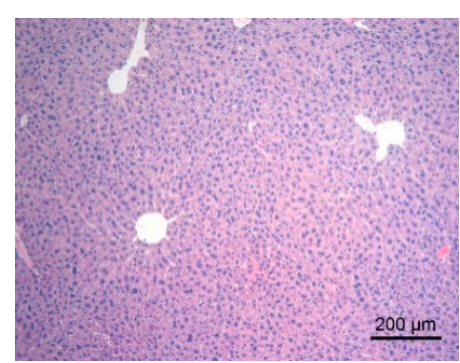

(C)

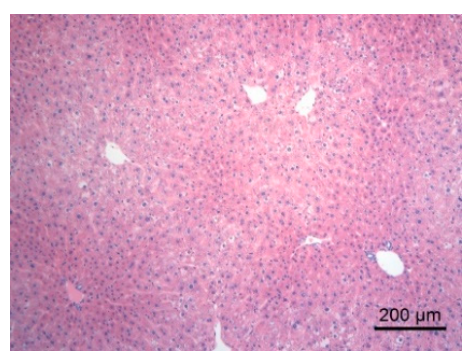

(F)

Figure 3. Pathological changes of liver tissues observed under light microscope. The representative areas of fatty degeneration of liver cells were indicated via black arrows, in which some fat droplets were observed under light microscope. (A) DM group, fatty degeneration of liver cells by approximately 80-90\%; (B) DMMET130 group, fatty degeneration and balloon denaturalization of liver cells by approximately $30-40 \%$ and $10-20 \%$; (C) Control group, normal morphology of liver cell; (D) DMDJP25 group, fatty degeneration of liver cells by approximately 70-80\%; (E) DMDJP50 group, by approximately 40-50\%; and (F) DMDJP100 group, by approximately $10-20 \%$.

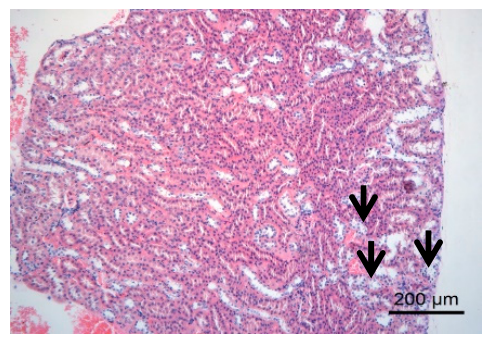

(A)

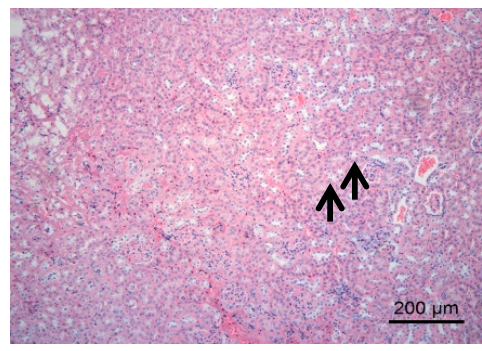

(D)

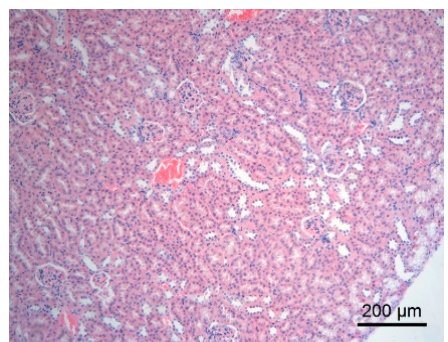

(B)

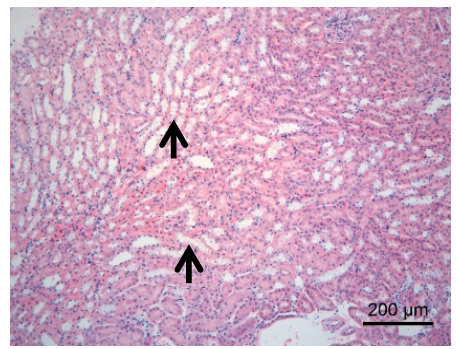

(E)

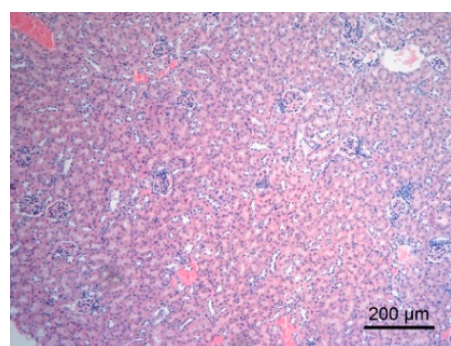

(C)

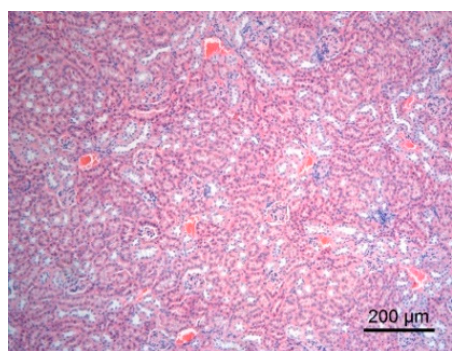

(F)

Figure 4. The pathological changes of kidney tissues observed under light microscope. The representative areas of vacuolar degeneration of renal tubular epithelial cells were indicated via black arrow, which appeared foam-like under light microscope. (A) DM group, vacuolar degeneration of renal tubular epithelial cells by approximately 21-40\%; (B) DMMET130 group, normal renal cortex and medulla; (C) Control group, normal renal cortex and medulla; (D) DMDJP25 group, vacuolar degeneration by approximately $21-40 \%$; (E) DMDJP50 group, vacuolar degeneration less than 20\%; (F) DMDJP100 group, normal renal cortex and medulla. 
Table 2. Grading of liver fatty degeneration/vacuolar degeneration of renal tubule epithelium cells in the mice.

\begin{tabular}{|c|c|c|c|c|c|c|c|c|c|c|}
\hline \multirow[t]{2}{*}{ Group } & \multirow[t]{2}{*}{$\mathbf{N}$} & \multicolumn{6}{|c|}{ Grading of Liver Fatty Degeneration } & \multicolumn{3}{|c|}{$\begin{array}{l}\text { Grading of Vacuolar Degeneration of } \\
\text { Renal Tubule Epithelium Cells }\end{array}$} \\
\hline & & 0 & + & ++ & +++ & ++++ & ++++ & 0 & ++ & +++ \\
\hline DM & 8 & 0 & 0 & 0 & 0 & 5 & 3 & 0 & 6 & 2 \\
\hline DMMET130*,1 & 8 & 3 & 0 & 0 & 1 & 2 & 2 & 8 & 0 & 0 \\
\hline Control & 8 & 8 & 0 & 0 & 0 & 0 & 0 & 8 & 0 & 0 \\
\hline DMDJP25 & 8 & 1 & 0 & 0 & 2 & 4 & 1 & 1 & 4 & 3 \\
\hline DMDJP50 \#, 2 & 8 & 3 & 2 & 0 & 1 & 2 & 0 & 2 & 4 & 2 \\
\hline DMDJP100 \#\#, 3, * & 6 & 1 & 1 & 2 & 2 & 0 & 0 & 6 & 0 & 0 \\
\hline
\end{tabular}

Date in Table 2 are the number of animals; Grading: $0=$ No change of histopathology; $+=$ less than $10 \%$ change of histopathology; $++=$ less than $25 \%$ change of histopathology; $+++=25-50 \%$ change of histopathology; $++++=50-75 \%$ change of histopathology; $+++++=>75 \%$ change of histopathology; ${ }^{1 *}=p<0.01$ vs. DM group (renal tissue); ${ }^{2}=p<0.05$ vs. DM group (liver tissue); ${ }^{3 \# \#}=p<0.01$ vs. DM group (liver tissue).

The kidney tissues in C57 control group was normal morphology. The renal tubule epithelium cells in DM group showed varying degrees of vacuolar degeneration; the renal lesion in DMDJP25 group and DMDJP50 group were not improved. The vacuolar degeneration of renal tubular epithelial cells was not observed in DMMET130 and DMDJP100 groups (Figure 4B,F and Table 2; $p<0.01$ vs. DM group).

\subsection{Effect of DJP on Inflammatory Factors}

To understand the anti-diabetic effect of DJP, the level of serum IL-6 was detected by ELISA and the level of TNF- $\alpha$ in the liver/kidney tissue were detected by immunohistochemistry. The results were showed in Figure 5, Figure 6, Figure 7 and Table 3, respectively.

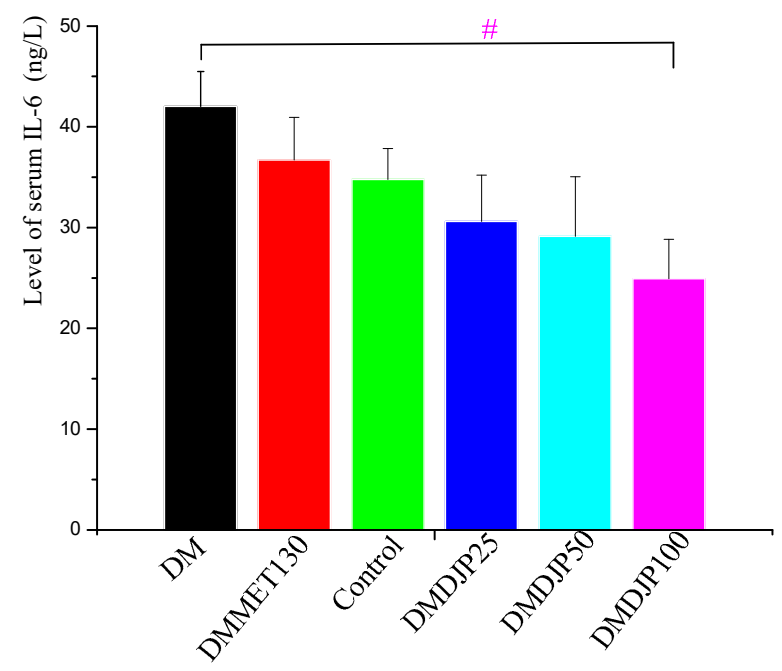

Figure 5. Level of serum IL-6 in the mice (ng/L). Data are mean $\pm \mathrm{SD} ; \#=p<0.05$ vs. DM group. 


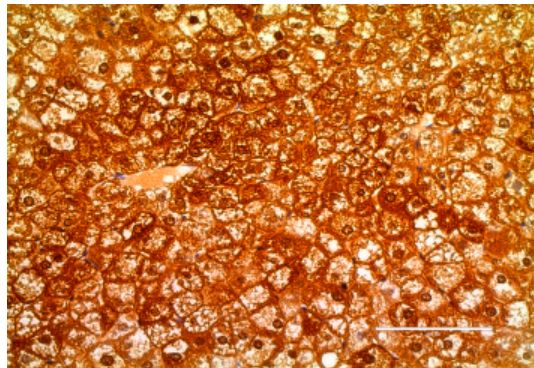

(A)

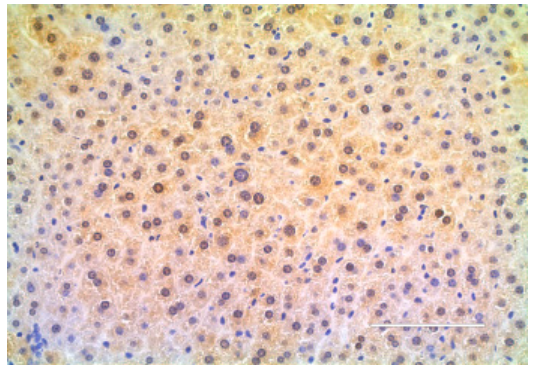

(C)

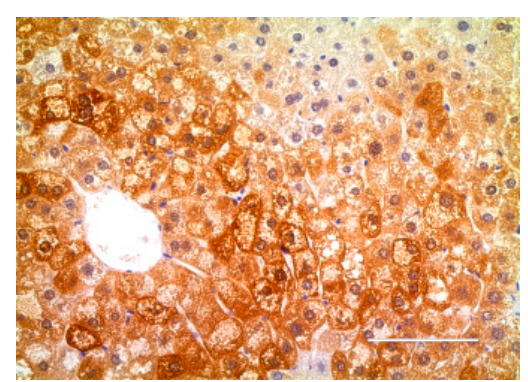

(B)

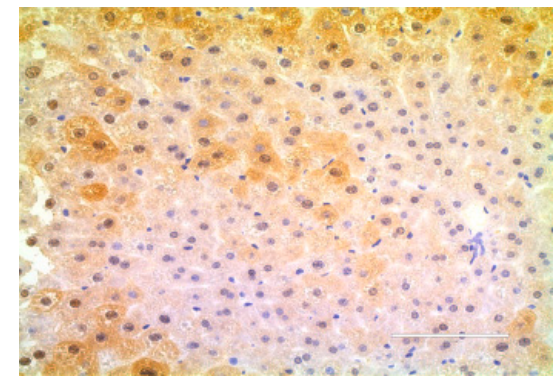

(D)

Figure 6. Expression of tumor necrosis factor- $\alpha$ (TNF- $\alpha)$ in the liver tissue detected by immunohistochemistry. The positive expressive areas of TNF- $\alpha$ are tan. (A) DM group; (B) DMMET130 group; (C) Control group; (D) DMDJP100 group.

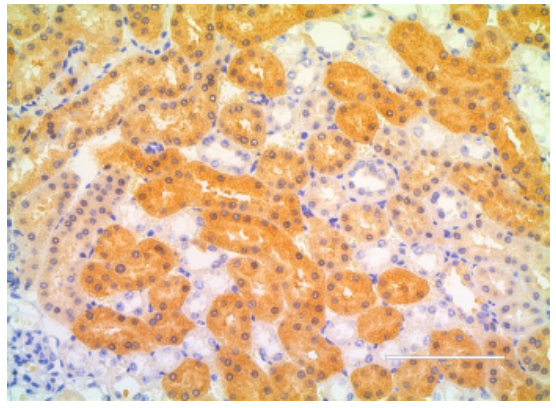

(A)

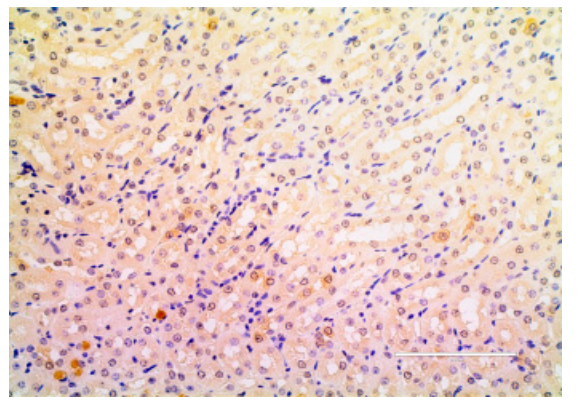

(C)

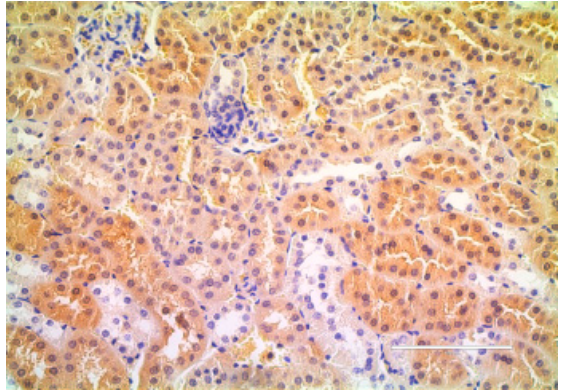

(B)

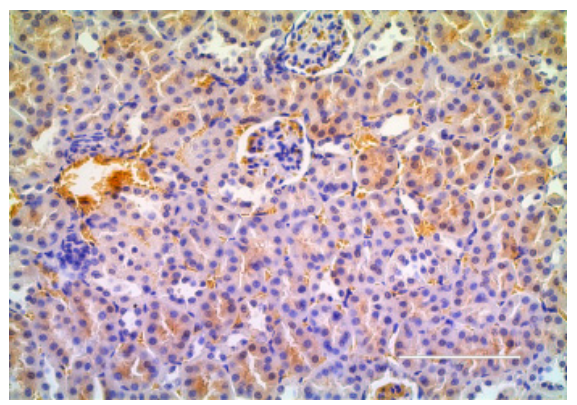

(D)

Figure 7. Expression of tumor necrosis factor- $\alpha$ (TNF- $\alpha$ ) in kidney tissue detected by immunohistochemistry. The positive expressive areas of TNF- $\alpha$ are tan. (A) DM group; (B) DMMET130 group; (C) Control group; (D) DMDJP100 group. 
Table 3. Immunohistochemical expression of TNF- $\alpha$ of liver/ kidney tissue in the mice.

\begin{tabular}{ccc}
\hline Group & Expression of TNF- $\alpha$ in Liver Tissue & Expression of TNF- $\alpha$ in Kidney Tissue \\
\hline DM & $0.21 \pm 0.03$ & $0.077 \pm 0.005$ \\
DMMET130 & $0.18 \pm 0.05$ & $0.110 \pm 0.002$ \\
Control & $0.069 \pm 0.006$ & $0.028 \pm 0.003$ \\
DMDJP100 & $0.088 \pm 0.005^{\# \#, 1}$ & $0.034 \pm 0.003^{\#, 2}$ \\
\hline
\end{tabular}

The data were mean of gray scale (IOD/area); ${ }^{1 \# \#}=p<0.01$ vs. DM group, ${ }^{2}{ }^{\#}=p<0.05$ vs. DM group.

Figure 5 revealed that the level of serum IL-6 in the treatment groups was lower than that of DM group; the three groups of DJP treatment displayed certain dosage-effect relationship. Compared with DM group, the level of serum IL-6 was significantly reduced in DMDJP100 group $(p<0.05)$.

Figure 6, Figure 7, and the gray-value in Table 3 showed that the relative expression amount of TNF- $\alpha$ in control group was the lowest level, while that in DM group had the highest level. The relative expression amount of TNF- $\alpha$ in DMDJP100 group was significantly reduced $(p<0.05$ in kidney tissue; $p<0.01$ in liver tissue, vs. DM group).

\subsection{Effect of DJP on Oxidative Stress Index}

To understand the anti-diabetic effect of DJP, SOD, MDA, CAT, and GSH levels of kidney/liver tissue were detected by ELISA. The results were showed in Table 4.

Table 4. Oxidative stress index of liver/kidney tissue in the mice.

\begin{tabular}{|c|c|c|c|c|c|c|}
\hline \multirow{2}{*}{ Tissue } & \multirow{2}{*}{\multicolumn{2}{|c|}{ Oxidative Stress Index }} & \multicolumn{4}{|c|}{ Group } \\
\hline & & & DM & DMMET130 & Control & DMDJP100 \\
\hline \multirow{4}{*}{ Liver } & GSH & \multirow{2}{*}{$\mu \mathrm{mol} / \mathrm{gprot}$} & $37.06 \pm 2.87$ & $40.58 \pm 2.61^{\#, 1}$ & $44.51 \pm 3.70$ & $41.86 \pm 3.43^{\#}$ \\
\hline & MDA & & $0.66 \pm 0.03$ & $0.34 \pm 0.05^{\# \#, 2}$ & $0.59 \pm 0.08$ & $0.44 \pm 0.05^{\# \#}$ \\
\hline & CAT & \multirow{2}{*}{$\mathrm{U} / \mathrm{mgprot}$} & $45.92 \pm 4.41$ & $57.48 \pm 4.27^{\# \#}$ & $47.21 \pm 1.59$ & $70.35 \pm 5.07^{\# \#}$ \\
\hline & SOD & & $161.5 \pm 5.9$ & $161.7 \pm 7.5$ & $205.8 \pm 8.7$ & $177.4 \pm 6.4^{\#}$ \\
\hline \multirow{4}{*}{ Kidney } & $\mathrm{GSH}$ & \multirow{2}{*}{$\mu \mathrm{mol} / \mathrm{gprot}$} & $27.88 \pm 2.26$ & $37.82 \pm 2.72 \#$ & $36.27 \pm 3.88$ & $33.38 \pm 3.09^{\#}$ \\
\hline & MDA & & $1.79 \pm 0.08$ & $1.38 \pm 0.13^{\# \#}$ & $1.31 \pm 0.15$ & $1.51 \pm 0.11^{\#}$ \\
\hline & CAT & \multirow{2}{*}{$\mathrm{U} / \mathrm{mgprot}$} & $12.43 \pm 5.23$ & $30.48 \pm 5.49$ & $30.11 \pm 3.34$ & $32.21 \pm 4.53^{\# \#}$ \\
\hline & SOD & & $83.65 \pm 6.8$ & $115.2 \pm 6.3^{\# \#}$ & $131.1 \pm 5.8$ & $111.0 \pm 5.6^{\#}$ \\
\hline
\end{tabular}

Table 4 revealed that the MDA of liver/kidney tissue were at high level in DM group, but GSH, CAT, and SOD were at low levels. After administration of DJP or MET, the MDA level were significantly decreased in DMDJP100 and DMMET130 groups; the GSH, CAT, and SOD levels of liver/kidney tissue were significantly increased.

\subsection{DJP on Modulation of Intestinal Microbiome}

\subsubsection{Taxonomic Characterization of Intestinal Microbiome}

A total of 1,383,220 high-quality sequences from 46 intestinal microbiome samples were produced and with an average of 30,070 sequences per sample. The high-quality sequences were delineated into 607 operational taxonomic units (OTUs) at $97 \%$ similarity. The detailed characteristics of each sample were listed in Table S2. The sequencing quality was evaluated by methods of rarefaction analysis based alpha diversity indexes (Figure 8). From Figure 8, we can see three rarefaction curves (Figure 8A chao1 index curve, 8B Shannon index curve and 8C Simpson index curve) tend to be flat or reach the plateau stage, which suggest the sequencing data were enough to cover all species in the microbiome community, and the most of the gut microbial diversity in each sample was captured with the current sequencing depth. 
Ten different bacterial phyla were identified in the mice intestinal microbiome. The majority of sequences obtained belonged to Bacteroidetes (46-61\%), Firmicutes (26-31\%), and Proteobacteria (5-16\%), followed by Verrucomicrobia, Deferribacteres, Cyanobacteria, Actinobacteria, Tenericutes, and TM7; unclassified bacteria were less $0.03 \%$ (Figure 9A). This composition was consistent with previous observations [32,33].

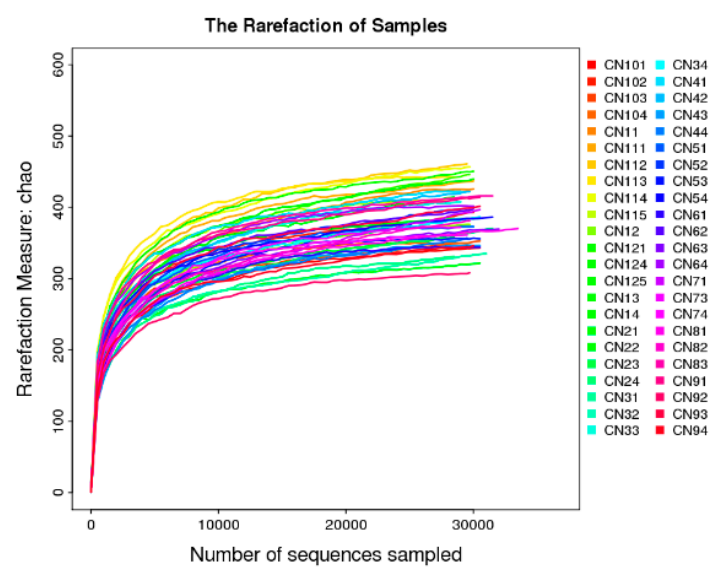

(A)

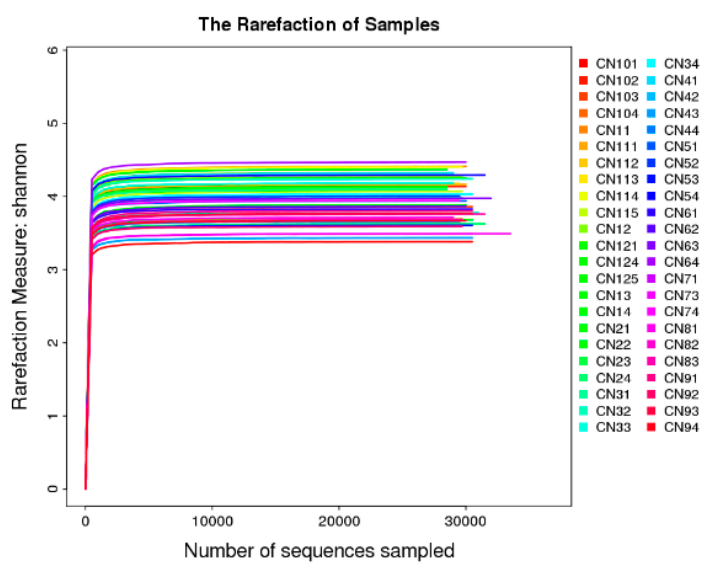

(B)

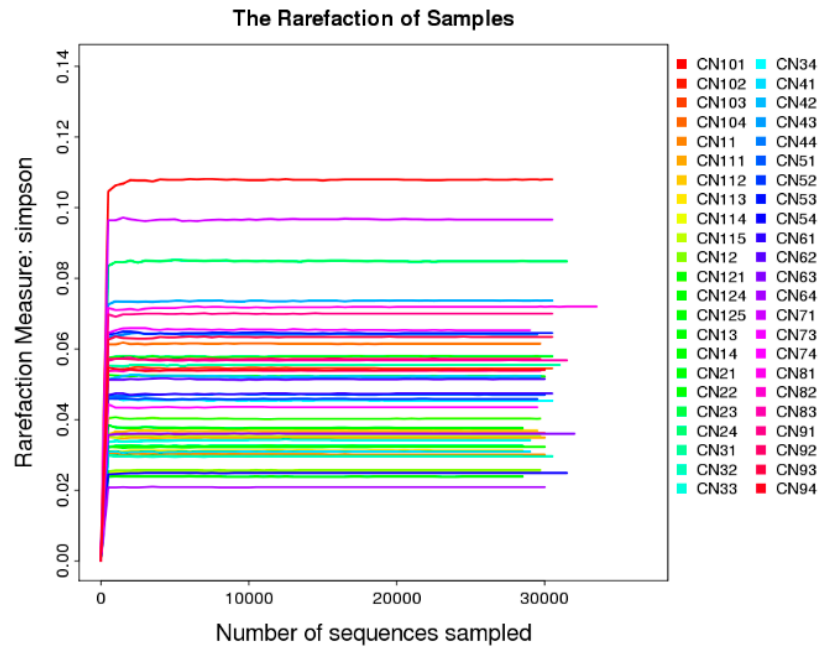

(C)

Figure 8. Rarefaction analysis curve based on alpha diversity. (A) Chao index rarefaction curve; (B) Shannon index rarefaction curve; (C) Simpson index rarefaction curve.

Figure 9B showed that the class Bacteroidia (61-46\%) and Clostridia (24-33\%) were the most abundant. The genera Oscillospira (5\%) and Prevotella (4\%) were the dominated microbiome in control group, and the genera Prevotella (11-26\%) and Bacteroides (8-18\%) were the predominance microbiome in the five $\mathrm{db} / \mathrm{db}$ mice groups. The genera Oscillospira, Prevotella, Akkermansia, and Mucispirillum were enriched in control group, whereas Prevotella and Bacteroides were enriched in the five groups of $\mathrm{db} / \mathrm{db}$ mice (Figure 9B,C). The genera Escherichia was enriched in DM group. A total of 11 species were detected in all 46 samples, which existed large differences of dominant species among the six mice groups (Figure 9C). 


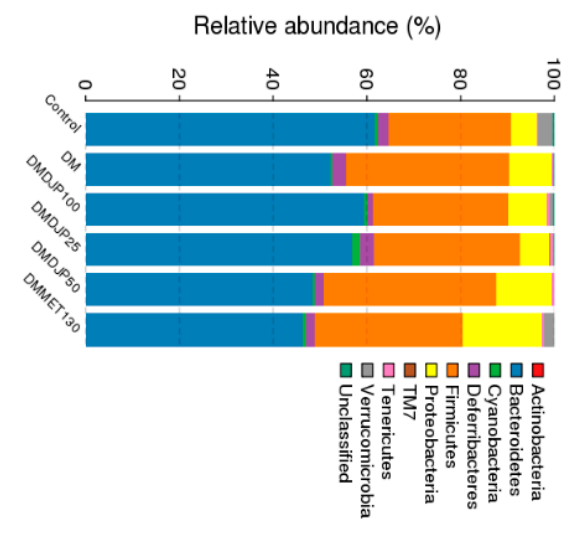

(A)

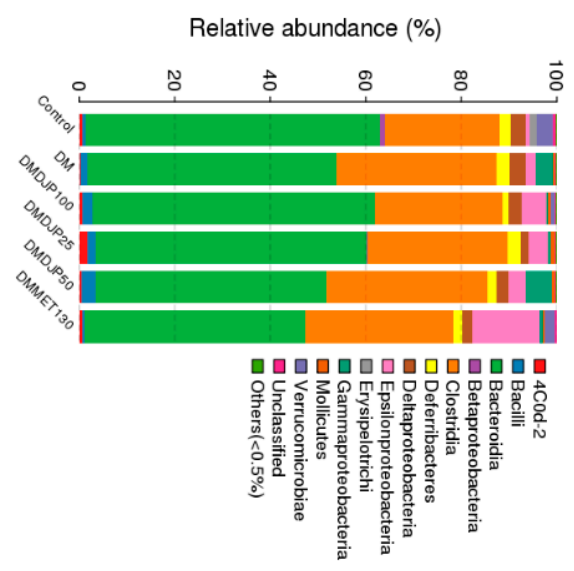

(B)

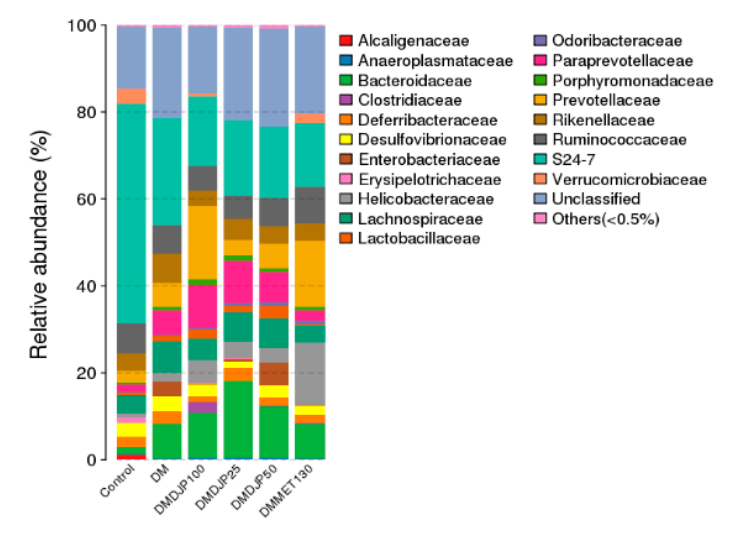

(C)

Figure 9. Taxonomic composition of gut microbiome in the mice. (A) Phylum-level; (B) Class-level; (C) Species-level.

\subsubsection{Distinct Microbial Composition}

The box-plot based on alpha diversity (Figure 10A) and the principal component analysis (PCA) based on the OTUs abundance (Figure 10B) displayed the differences of microbial composition among the six groups. The distribution of OTUs abundance was similarity between DMMET130 and DMDJP100 groups; the distribution of abundance in DM group was the same as that of DMDJP25 group; the abundance of microbial composition in control group was separated from the five $\mathrm{db} / \mathrm{db}$ mice groups for mutated gene. 

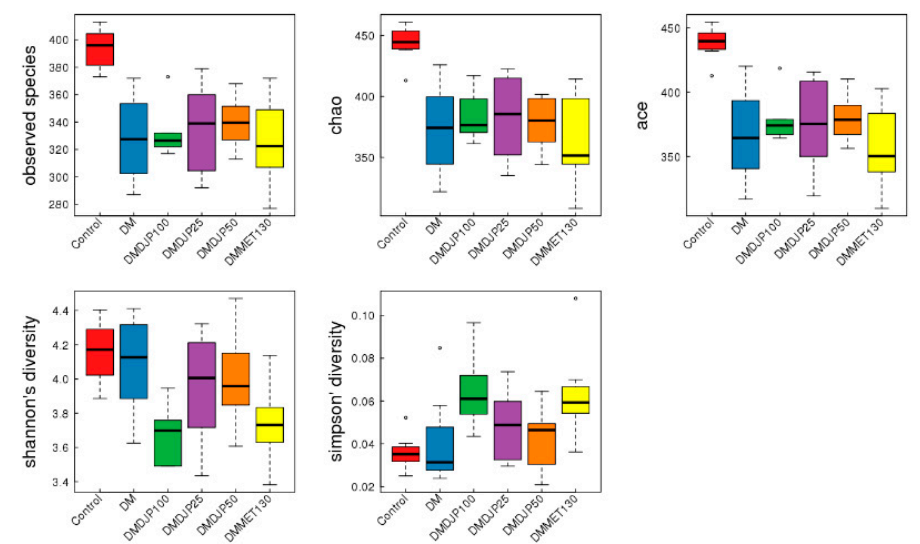

(A)

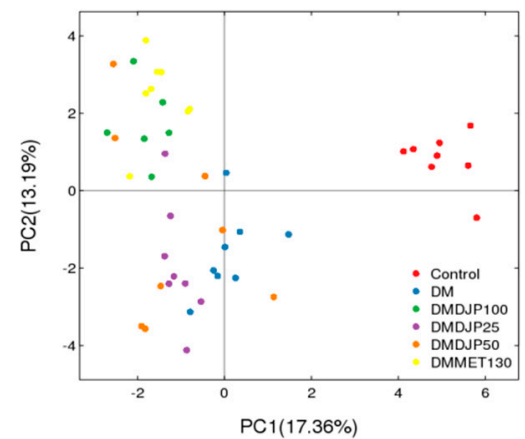

(B)

Figure 10. Alpha diversity indices box-plots and principal component analysis (PCA) plots based on operational taxonomic units (OTUs) abundance. (A) box-plots; (B) PCA plots

\subsubsection{Functional Predictions of Gut Microbiome}

The taxa predicted by 16S RNA marker gene sequencing in the six groups were functionally assigned to KEGG (Kyoto Encyclopedia of Genes and Genomes) pathways, and the proportion of sequences (\%) were assessed. A total of 328 pathways were detected in the six groups making up the core metabolic functions in the cohort. Overall, the six groups tended to share more similar abundances of sequences families. About $50 \%$ of the gut microbiome in almost every group were enriched on KEGG metabolism pathways, such as, carbohydrate metabolism (about 10\%), amino acid metabolism (about 9\%), energy metabolism (about 6\%), metabolism of cofactors and vitamins (about $4 \%$ ), nucleotide metabolism (about $4 \%$ ), glycan biosynthesis and metabolism (about 3\%), lipid metabolism (about 3\%), and enzyme families (about 2\%). Using a $p<0.05$ for ANOVA tests in STAMP, several statistical differences were found between DMDJP100 group and DM group (Figure S2).

\section{Discussion}

T2DM was called "Wasting and Thirsting Disorder" in ancient Chinese medicine. Shi-Hu, as a "nourishing Yin and invigorating Qi" herb, is the main component of some prescriptions for diabetes [34]. In recent years, the pharmacology and mechanism of Dendrobium for diabetes attracted many researchers; however, much attention of researchers were paid on the ethanolic/water extracts, polysaccharide or alkaloid of Dendrobium [26,34]. The present study was the first work on the effects of anti-diabetic and improving complications of Dendrobium rich-polyphenols extract.

T2DM complications, such as nephropathy, adiposis hepatica, hypertension, stroke, or ophthalmopathy are some of the causes of high mortality. Some antioxidants and anti-inflammatory agents were used for treatment of diabetes and its complications [35]. Brasnyó et al. reported that resveratrol improved insulin sensitivity in T2DM due to decrease in oxidative stress, expression of NF-kB, JNK, TNF- $\alpha$, and IL-6 [36]. It was reported that curcusome had renoprotective effects by inhibiting renal lipid accumulation and oxidative stress through AMPK and Nrf2 signaling pathway [37]. DJP (Table S1) and its phenols components showed anti-inflammation and antioxidant activities in vitro [29]; the present study demonstrated that DJP (in a dose of $100 \mathrm{mg} / \mathrm{kg}$ ) can significantly decrease the blood glucose, LDL-C, insulin resistance and increase serum INS level in $\mathrm{db} / \mathrm{db}$ mice. In addition, DJP obviously alleviated the fatty degeneration of liver cells and vacuolar degeneration of renal tubule epithelium cells in the mice. ELISA and immunohistochemical analysis revealed that DJP induced the decreasing oxidative stress, IL-6 and TNF- $\alpha$. It is supposed that the anti-inflammatory and antioxidant activities might be a mechanism for DJP anti-diabetes action. 
The intestinal microbiome consists of a complex microbes community that impact normal physiology and susceptibility to disease mediated by inflammatory molecules such as lipopolysaccharides and peptidoglycans [38,39]. It was reported that the intestinal flora of diabetic patients are significant difference from non-diabetic adults [40]; it has been verified that the Bacteroidetes to Firmicutes ratio was decreased in T2DM individuals [41]. The decrease in Bacteroidetes and the increase in Firmicutes could be related with the presence of genes encoding enzymes that break down polysaccharides, which was associated with the increased capacity to harvest energy from food, and caused low-grade systemic inflammation [42,43]. In $\mathrm{db} / \mathrm{db}$ animal model, the Bacteroidetes and Firmicutes ratio was significant reduction [33]. In this study, we observed that Bacteroidetes to Firmicutes ratio was increased in DMDJP100 group compared with DM group (Figure 9A), which revealed that the intestinal flora imbalance was improved after 8 weeks of DJP treatment.

It was reported that the abundance of Akkermansia. muciniphila was decreased in obese and T2DM mice [44]. Several different research groups confirmed that the increased relative abundance of Akkermansia sp. may be a new anti-hyperglycemic mechanism of metformin $[45,46]$. In the present work, we observed that the relative abundance of Akkermansia muciniphila was increased in DMDJP100 group as that of DMMET130 group, which was almost 24 times more than the level of DM group (Figure 11). It is suggested that the increase of relative abundance of Akkermansia sp may contribute to DJP anti-diabetic effect.

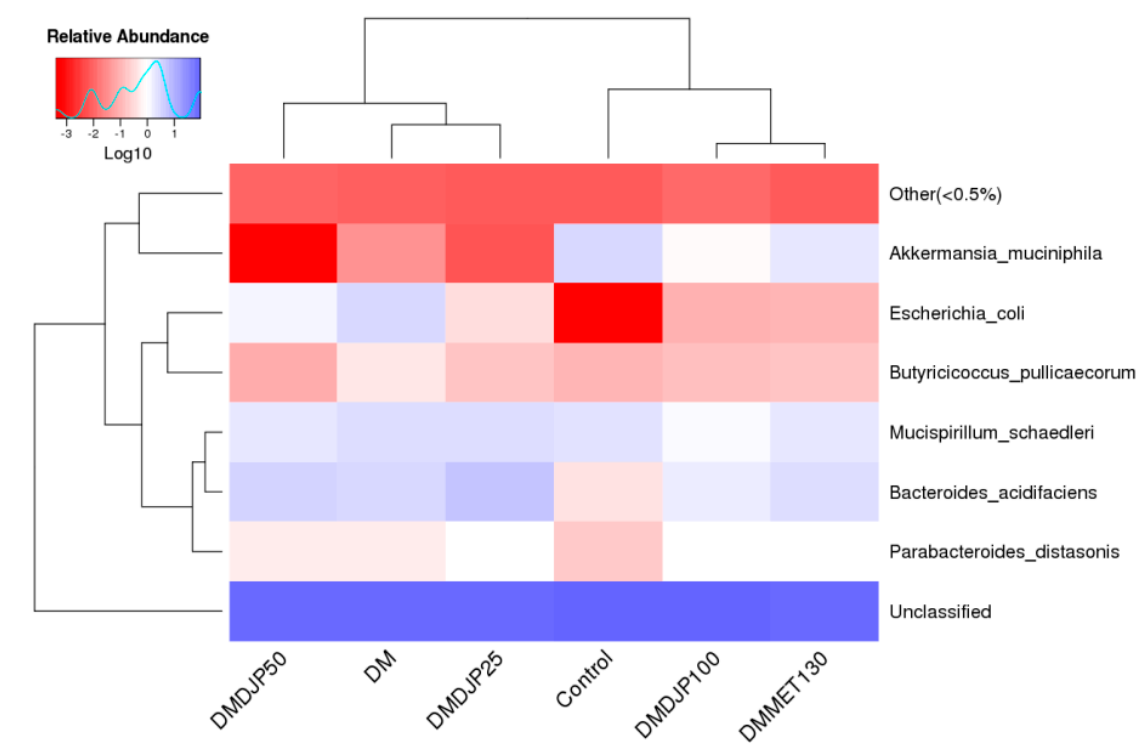

Figure 11. The heat map of species-level of the mice.

It was reported that Escherichia coli was increased in both obese and T2DM subjects [47]. Escherichia coli can produce a material very similar to insulin, which was found to block insulin by binding to the target cell of insulin and leads to diabetes [48]. Escherichia coli are intestinal mucosal adherence, and associated with a low-grade inflammation [49]. In present work, the relative abundance of Escherichia was significantly decreased in DMDJP100 group ( $p<0.05$ vs. DM group; Figure 11, Figure 12 and Table S3). It was suggested that DJP improved the mice gut health by gut microbiota modulation, which might be a mechanism for DJP anti-diabetes action. 
DM-DMDJP100

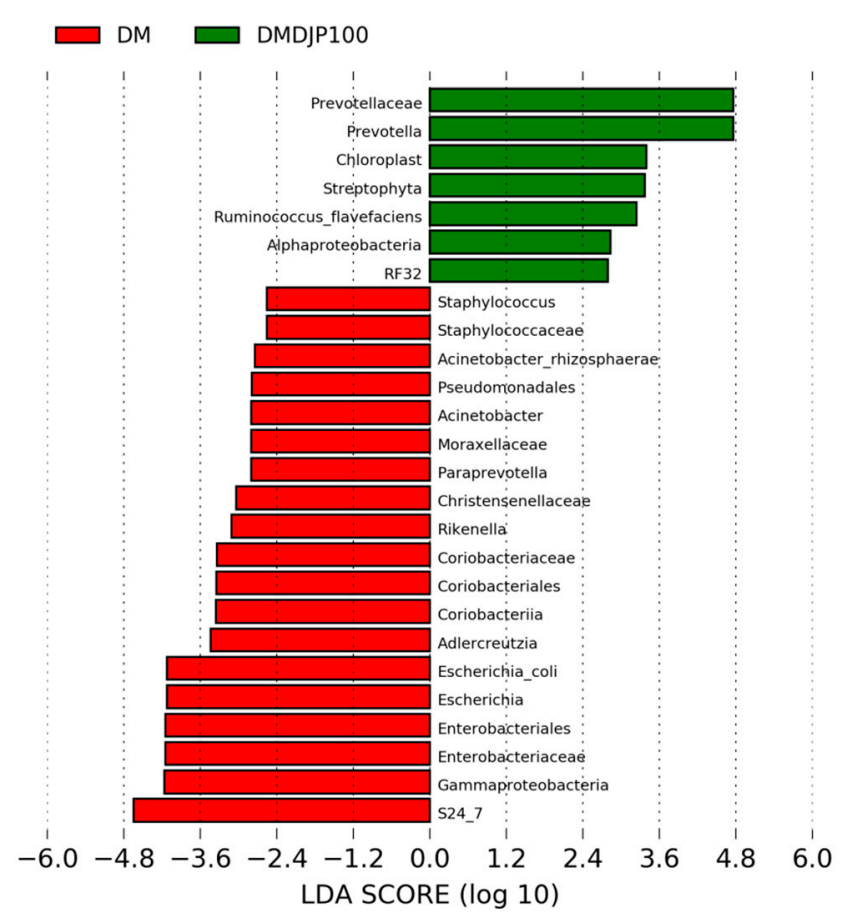

Figure 12. Identification of taxonomic features relevant in DM and DMDJP100 using LEfSe (LDA Effect Size).

In this study, we identified several compositional variations of intestinal microbiome (Figure 11, Figure 12 and Table S3), such as, the relative abundance of Prevotellaceae (Bacteroidetes) was significantly increased in DM DJP100 group; the relative abundance of S24-7 (Bacteroidetes) and Rikenella (Bacteroidetes) were significantly decreased ( $p<0.05$ vs. DM group). Monk et al. reported that Prevotella and S24-7 are carbohydrate fermenting and short chain fatty acid (SCFA) production bacteria [50]; SCFA can enhance the barrier function of colonic epithelium [51]. Rikenella was sulfatase-secreting bacteria [52], which induced the increase levels of bacterial endotoxinemia and chronic low-grade inflammation [53]. It was suggested that the changes of intestinal flora decreased inflammation and enhanced the mucus/epithelial barrier integrity in DMDJP100 group.

Functional annotation analyses showed that some proportion of sequences involved in individual metabolic pathways in DMDJP100 group are significantly different compared to DM group $(p<0.05$, Figure S2), such as, the significant decline of bacteria responsible for butanoate metabolism (carbohydrate metabolism)/fatty acid metabolism (lipid metabolism), and the significant increase of bacteria responsible for fatty acid biosynthesis (lipid metabolism)/arachidonic acid metabolism (lipid metabolism) in DM DJP100 group ( $p<0.05$ vs. DM group), which indicated that DJP induced an important change of carbohydrate metabolism and lipid metabolism by the modulation of the gut microbiota.

The functional annotation analyses allowed to identify associated pathways and therefore can predict functional capabilities, but its limitations are the small sample size. To further confirm functional differences before and after treatment, quantification of messenger RNA and metabolic profiling are needed. In spite of this, our study suggested that the changes of intestinal microbiome may markedly contribute to DJP anti-hyperglycemic effects. 


\section{Materials and Methods}

\subsection{Materials and Reagents}

The dried stems of $D$. loddigesii (from Yunnan Province, China) were purchased in September 2015 from Caizilin Pharmacy in Guangzhou, China and identified with the classical method by pharmaceutical botanist Prof. Lin Jiang, School of Pharmaceutical Sciences, Sun Yat-Sen University. The voucher sample (No. 201509131) was deposited in the School of Pharmaceutical Sciences, Sun Yat-Sen University (Guangzhou, China). The reference compounds including moscatilin, gigantol, 2,4,7-trihydroxyl-9,10-dihydrophenanthrene, and tristin were isolated previously [27].

TNF- $\alpha$ antibody and horseradish peroxidase (HRP) conjugated anti-mouse IgG were purchased from Wuhan Servicebio Technology Co., Ltd (Wuhan, China). E.Z.N.A. ${ }^{\circledR}$ Bacterial DNA Kit was purchased from Omega Bio-tek (Norcross, GA, US); ELISA kits were purchased from Nanjing Jiancheng Institute of Bioengineering (Jiangsu, China). Metformin hydrochloride and sodium carboxymethylcellulose (NaCMC) were purchased from Sigma Chemical Co. (St. Louis, MO, USA); Chemical reagents were purchased from Guangzhou Chemical Reagent Factory (Guangzhou, China).

\subsection{Preparation Rich-Polyphenols Extract of D. Loddigesii}

The dry stems of $D$. loddigesii $(1 \mathrm{~kg})$ were extracted with acetone-water solution $(80: 20, v / v ; 3 \times 5 \mathrm{~L})$ at room temperature to generate $70 \mathrm{~g}$ of crude extract. The crude extract was dissolved in methanol, deposited on a column of RP-18 gel, and eluted with water, then, water-methanol solution (15:85, $v / v)$. The water-methanol eluate was evaporated to dryness to give the rich-polyphenols extract of D. loddigesii ( $28 \mathrm{~g}), 2.8 \%$ of the weight of raw materials.

The rich-polyphenols extract of $D$. loddigesii (DJP) was subjected to liquid chromatography fingerprint analysis in which major peaks were identified as the marker compounds of their originating herbs [27]; the rich-polyphenols extract of $D$. loddigesii was used in the current pharmacologic study.

\subsection{Animal Experiments}

Eight mice of C57BL/6 (male, 6-8 weeks old) and forty mice of BKS.Cg-Dock7m +/+Leprdb/Nju ( $\mathrm{db} / \mathrm{db}$ mice, male, 6-8 weeks old) were purchased from Nanjing Biomedical Research Institute of Nanjing University (Approval No. SCXK (SU) 2015-0001). All the mice were included in the current study. Animal experiments were approved and performed in accordance with the guidelines by Institutional Animal Care and Use Committee (IACUC) Sun Yat-sen University, Approval No. IACUC-DD-17-0604. Animal experiments were performed in accordance with the guidelines in Laboratory Animal Center of Sun Yat-sen University, Number of Animal Use Permit: SYSK (YU): 2011-0112. The mice were kept under controlled light conditions (12 h light-dark cycle) with free access to food and water. A standard diet for mice was provided by Laboratory Animal Center of Sun Yat-sen University. All efforts were made to minimize animal suffering.

After one week' acclimatization, the $40 \mathrm{db} / \mathrm{db}$ mice were randomly distributed into five groups: (1) DM model group $(\mathrm{n}=8)$; (2) DMMET130 group $(\mathrm{n}=8$, with metformin hydrochloride in a dose of $130 \mathrm{mg} / \mathrm{kg}$ ); (3) DMDJP25 group ( $\mathrm{n}=8$, with DJP in a dose of $25 \mathrm{mg} / \mathrm{kg}$ ); (4) DMDJP50 group ( $\mathrm{n}=8$, with DJP in a dose of $50 \mathrm{mg} / \mathrm{kg}$ ); (5) DMDJP100 group ( $=6-8$, with DJP in a dose of $100 \mathrm{mg} / \mathrm{kg}$ ). The C57BL $/ 6$ mice were control group $(n=8)$, respectively.

All the drugs, DJP and metformin hydrochloride were given to the mice by gavage in $0.6 \%$ $\mathrm{NaCMC}$ solution. Non-treatment groups, DM model group and C57 control group, were given the same volume of $0.6 \% \mathrm{NaCMC}$ solution to minimize the effects of gavage procedure. Two mice died for the reasons unrelated to the experiments in DMDJP100 group.

The drugs were administered once a day and for 8 consecutive weeks. Throughout the duration of trial, the blood glucose level and body weight of each mouse were monitored once a week. OGTT test was performed at the 7 th week. 
At the end of the trial, all the mice were sacrificed by cervical dislocation. The tissues were excised and frozen in liquid nitrogen, or $10 \%$ formalin solution immediately for further analysis. The contents of cecum and colon were sampled, weighed and immediately frozen in liquid nitrogen (46 in total), then, these gut samples were stored at $-80{ }^{\circ} \mathrm{C}$ until DNA extraction.

\subsection{Blood Glucose and ELISA Analysis}

Blood glucose level were determined on $3.5 \mu \mathrm{L}$ of blood collected from the tip of the tail vein using a glucose meter, Accu-Chek Performa (Roche Diagnostics GmbH, Mannheim, Germany). OGTT test was performed as following: after fasting for $12 \mathrm{~h}$, the mice were received $20 \% \mathrm{D}$-glucose solution by gavage in a dose of $2 \mathrm{~g} / \mathrm{kg}$, then, blood glucose level were measured at $0,30,60,90$, and $120 \mathrm{~min}$ following the glucose challenge.

The concentrations of TG, TC, HDL, LDL, INS and IL-6 in serum were determined using a commercial ELISA kit based on the manufacturer's instructions. The levels of GSH, MDA, SOD and CAT in tissue samples from the mice kidney/liver were measured using a commercial ELISA kit based on the manufacturer's instructions. A multi-mode microplate reader FlexStation 3 (Molecular devices, Sunnyvale, CA, USA) was used for ELISA testing.

\subsection{Histologic Analysis}

Freshly isolated tissues of liver as well as kidney were fixed overnight in $10 \%$ formalin solution, embedded in paraffin, cut into $3 \mu \mathrm{m}$ thick sections, and stained with haematoxylin \& eosin. The histological tissue damage of liver/kidney was observed using a LEICA DM5000B microscope (Leica, Heidelberg, Germany).

\subsection{Immunohistochemical Analysis of TNF- $\alpha$}

Paraffin-embedded tissues sections $(5 \mu \mathrm{m})$ were deparaffinized in xylene, rehydrated in a gradient of ethanol-water ( $85 \%$ ethanol, $5 \mathrm{~min} ; 75 \%$ ethanol, $5 \mathrm{~min}$, then distilled water). Their antigen was repaired with EDTA antigen retrieval solution ( $\mathrm{pH} 9.0)$; the endogenous peroxidase was quenched; the specific binding sections were blockaded by $3 \%$ bovine serum albumin. Then, the sections were incubated overnight at $4{ }^{\circ} \mathrm{C}$ with TNF- $\alpha$ antibody, with HRP conjugated anti-mouse IgG 50 mine, and were counterstained with hematoxylin. Images were taken under a FL Auto Imaging System+ EVOS $^{\circledR}$ Onstage Incubator (Life Technologies Corporation, CA, USA). The gray values were calculated using Image-Pro Plus 6.0 (Media Cybernetics, Inc., MA, USA).

\section{7. $16 \mathrm{~S}$ rRNA Gene Extraction, Amplification and Sequencing}

The gut microbiome samples were sent to BGI Co., Ltd, China (Shenzhen, China) for DNA extraction and sequencing of $16 \mathrm{~S}$ rRNA gene. Total genomic DNA of the gut microbiome was extracted using E.Z.N.A. ${ }^{\circledR}$ Bacterial DNA Kit (Omega Bio-tek, Norcross, GA, USA) according to manufacturer's instruction. The V4 of 16S rRNA gene from the single gut microbiome sample was amplified. After genome DNA was normalized to $30 \mathrm{ng}$ per PCR reaction, V4 dual-index fusion PCR primer cocktail and PCR master mix were added, then to run PCR. The melting temperature was $56{ }^{\circ} \mathrm{C}$ and PCR cycle was 30. The PCR products were purified with AmpureXP beads to remove the unspecific products. The resulting library was used for sequencing on Illumina HiSeq 2500 platform following the standard pipelines of Illumina, and generating $2 \times 250$ bp paired-end reads [54].

\subsection{Statistical and Bioinformatics Analysis}

To obtain clean reads, the raw data were filtered to eliminate the adapter pollution and low-quality reads by an in-house procedure as following [55]: The clean paired-end reads with overlap were merged to tags using FLASH (fast length adjustment of short reads, v1.2.11) [56]. Then, the tags were clustered to OTUs at 97\% sequence similarity by scripts of software USEARCH (v9.1.13) [57]. 
Taxonomic ranks were assigned to OTUs representative sequence using Greengene (v201305, http://greengenes.secondgenome.com/downloads) [58]. At last, alpha diversity, beta diversity and the different species screening were analyzed based on OTUs and taxonomic ranks using mothur (v1.31.2), software R (v3.1.1), QIIME (v1.80), or metastats (http:/ / metastats.cbcb.umd.edu/) [59,60].

\subsection{Predicted Metabolic Profile}

To predict the functional profile of the gut microbiome, the OTUs from the closed reference script were assigned to orthologous groups from the Kyoto Encyclopedia for Genes and Genomes using software PICRUSt [61,62].

\section{Conclusions}

Our study revealed that the rich-polyphenols extract of $D$. loddigesii (DJP) has the ability to improve the $\mathrm{db} / \mathrm{db}$ mice symptoms of diabetes and complications, which might be the synergistic effects of all phenols of DJP. The anti-diabetic mechanism of DJP might be attributed to its antiinflammation as well as anti-oxidatin and improving balance of intestinal flora.

Supplementary Materials: The following are available online, Figure S1: Principal components of rich-polyphenols extract from D. loddigesii; Figure S2: Metabolic differences between DM and DMDJP100 groups. Table S1: Biological activities of rich-polyphenols extract of $D$. loddigesii (DJP) in vitro; Table S2: OTUs statistics detail, Table S3: DM-DMDJP100 differentially abundant (Family).

Author Contributions: H.-Y.H. and J.W. designed the study; X.-W.L. and Y.Y.-H. performed the biological assay; H.-P.C. and J.-W.C. performed the animal experiments; W.-L.C. performed the preparation and analysis of polyphenols; L.G. performed statistical analyses and prepared the figures. J.W. and H.-Y.H. interpreted the data, wrote and revised the paper. All authors reviewed the paper. X.-W.L. and H.-P.C. contributed equally to this work.

Funding: This research was funded by the Department of Science and Technology of Guangdong Province (No. 2014A020221006; No. 2015A030313119); National Natural Science Foundation of China (No. 81473154; No. 81773659); Fundamental Research Funds for central universities (No. 18ykzd08) and Traditional Chinese Medicine Bureau of Guangdong Province (No. 20141052).

Acknowledgments: The authors thank BGI Co., Ltd for sequencing of 16S rRNA gene and statistical analysis.

Conflicts of Interest: The authors declare no conflict of interest.

\section{Abbreviations}

$\begin{array}{ll}\text { C57 control } & \text { no-treatment C57 mice } \\ \text { CAT } & \text { catalase } \\ \text { DJP } & \text { rich-polyphenols extract of } D \text {. loddigesii } \\ \text { DM } & \text { no-treatment diabetes } \mathrm{db} / \mathrm{db} \text { mice } \\ \text { DMDJP100 } & \text { DJP-treatment diabetes } \mathrm{db} / \mathrm{db} \text { mice, in a dose of } 100 \mathrm{mg} / \mathrm{kg} \\ \text { DMDJP25 } & \text { DJP-treatment diabetes } \mathrm{db} / \mathrm{db} \text { mice, in a dose of } 25 \mathrm{mg} / \mathrm{kg} \\ \text { DMDJP50 } & \text { DJP-treatment diabetes } \mathrm{db} / \mathrm{db} \text { mice, in a dose of } 50 \mathrm{mg} / \mathrm{kg} \\ \text { DMMET130 } & \text { MET-treatment diabetes } \mathrm{db} / \mathrm{db} \text { mice, in a dose of } 130 \mathrm{mg} / \mathrm{kg} \\ \text { GSH } & \text { glutathione } \\ \text { HDL-C } & \text { high density lipoprotein cholesterol } \\ \text { IL-6 } & \text { interleukin-6 } \\ \text { INS } & \text { insulin } \\ \text { LDL-C } & \text { low density lipoprotein cholesterol } \\ \text { MDA } & \text { malondialdehyde } \\ \text { MET } & \text { metformin } \\ \text { OGTT } & \text { oral glucose tolerance } \\ \text { OTUs } & \text { operational taxonomic units } \\ \text { PCA } & \text { principal component analysis } \\ \text { SCFA } & \text { short chain fatty acid } \\ \text { SOD } & \text { superoxide dismutase } \\ & \end{array}$


T2DM Type 2 diabetes mellitus

TC total cholesterol

TG triglyceride

TNF-a tumor necrosis factor-a

\section{References}

1. Ogurtsova, K.; da Rocha Fernandes, J.D.; Huang, Y.; Linnenkamp, U.; Guariguata, L.; Cho, N.H.; Cavan, D.; Shaw, J.E.; Makaroff, L.E. IDF Diabetes Atlas: Global estimates for the prevalence of diabetes for 2015 and 2040. Diabetes Res. Clin. Pract. 2017, 128, 40-50. [CrossRef] [PubMed]

2. Palem, S.P.; Abraham, P. A Study on the level of oxidative stress and inflammatory markers in type 2 diabetes mellitus patients with different treatment modalities. J. Clin. Diagn. Res. 2015, 9, BC04-7. [CrossRef]

3. Brownlee, M. The pathobiology of diabetic complications: A unifying mechanism. Diabetes 2005, 54, 1615-1625. [CrossRef] [PubMed]

4. Salabei, J.K.; Lorkiewicz, P.K.; Mehra, P.; Gibb, A.A.; Haberzettl, P.; Hong, K.U.; Wei, X.; Zhang, X.; Li, Q.; Wysoczynski, M.; et al. Type 2 diabetes dysregulates glucose metabolism in cardiac progenitor cells. J. Biol. Chem. 2016, 291, 13634-13648. [CrossRef] [PubMed]

5. Coomer, M.; Essop, M.F. Differential hexosamine biosynthetic pathway gene expression with type 2 diabetes. Mol. Genet. Metab. Rep. 2014, 1, 158-169. [CrossRef] [PubMed]

6. Wang, M.; Wang, X.C.; Zhao, L.; Zhang, Y.; Yao, L.L.; Lin, Y.; Peng, Y.D.; Hu, R.M. Oligonucleotide microarray analysis reveals dysregulation of energy-related metabolism in insulin-sensitive tissues of type 2 diabetes patients. Genet. Mol. Res. 2014, 13, 4494-4504. [CrossRef] [PubMed]

7. Mizukami, H.; Takahashi, K.; Inaba, W.; Tsuboi, K.; Osonoi, S.; Yoshida, T.; Yagihashi, S. Involvement of oxidative stress-induced DNA damage, endoplasmic reticulum stress, and autophagy deficits in the decline of $\beta$-cell mass in Japanese type 2 diabetic patients. Diabetes Care 2014, 37, 1966-1974. [CrossRef] [PubMed]

8. Liu, C.; Feng, X.; Li, Q.; Wang, Y.; Li, Q.; Hua, M. Adiponectin; TNF- $\alpha$ and inflammatory cytokines and risk of type 2 diabetes: A systematic review and meta-analysis. Cytokine 2016, 86, 100-109. [CrossRef] [PubMed]

9. Fathy, S.A.; Mohamed, M.R.; Ali, M.A.M.; Elhelaly, A.E.; Alattar, A.T. Influence of IL-6, IL-10, IFN- $\gamma$ and TNF- $\alpha$ genetic variants on susceptibility to diabetic kidney disease in type 2 diabetes mellitus patients. Biomarkers 2018, 31, 1-13. [CrossRef] [PubMed]

10. Esteve, E.; Ricart, W.; Fernández-Real, J.M. Gut microbiota interactions with obesity, insulin resistance and type 2 diabetes: Did gut microbiote co-evolve with insulin resistance? Curr. Opin. Clin. Nutr. Metab. Care 2011, 14, 483-490. [CrossRef]

11. Diamant, M.; Blaak, E.E.; De Vos, W.M. Do nutrient-gut microbiota interactions play a role in human obesity, insulin resistance and type 2 diabetes? Obes. Rev. 2011, 12, 272-281. [CrossRef] [PubMed]

12. Turnbaugh, P.J.; Bäckhed, F.; Fulton, L.; Gordon, J.I. Diet-induced obesity is linked to marked but reversible alterations in the mouse distal gut microbiome. Cell. Host. Microbe 2008, 3, 213-223. [CrossRef]

13. Neacsu, O.; Cleveland, K.; Xu, H.; Tchkonia, T.T.; Kirkland, J.L.; Boney, C.M. IGF-I attenuates FFA-induced activation of JNK1 phosphorylation and TNF- $\alpha$ expression in human subcutaneous preadipocytes. Obesity 2013, 21, 1843-1849. [CrossRef] [PubMed]

14. Compare, D.; Rocco, A.; Sanduzzi Zamparelli, M.; Nardone, G. The gut bacteria-driven obesity development. Dig. Dis. 2016, 34, 221-229. [CrossRef] [PubMed]

15. China Pharmacopoeia Committee. Chinese Pharmacopoeia; China Medical Science Press: Beijing, China, 2010; pp. 85-86.

16. Xu, J.; Han, Q.B.; Li, S.L.; Chen, X.J.; Wang, X.N.; Zhao, Z.Z.; Chen, H.B. Chemistry, bioactivity and quality control of Dendrobium, a commonly used tonic herb in traditional Chinese medicine. Phytochem. Rev. 2013, 12, 341-367. [CrossRef]

17. Qu, X.Y.; Wu, Y.X.; Zhang, J.L. Research advances on chemical constituents and pharmacological activities of Dendrobium. Tianjin Agric. Sci. 2015, 21, 19-32.

18. Miyazawa, M.; Shimamura, H.; Nakamura, S.; Kameoka, H. Antimutagenic activity of gigantol from Dendrobium nobile. J. Agric. Food Chem. 1997, 45, 2849-2953. [CrossRef] 
19. Miyazawa, M.; Shimamura, H.; Nakamura, S.; Sugiura, W.; Kosaka, H.; Kameoka, H. Moscatilin from Dendrobium nobile, a naturally occurring bibenzyl compound with potential antimutagenic activity. J. Agric. Food Chem. 1999, 47, 2163-2167. [CrossRef]

20. Chen, T.H.; Pan, S.L.; Guh, J.H.; Liao, C.H.; Huang, D.Y.; Chen, C.C.; Teng, C.M. Moscatilin induces apoptosis in human colorectal cancer cells: A crucial role of c-Jun NH2-terminal protein kinase activation caused by tubulin depolymerization and DNA damage. Clin. Cancer Res. 2008, 14, 4250-4258. [CrossRef]

21. Chen, C.C.; Wu, L.G.; Ko, F.N.; Teng, C.M. Antiplatelet aggregation principles of Dendrobium loddigesii. J. Nat. Prod. 1994, 57, 1271-1274. [CrossRef]

22. Liu, Y.N.; Pan, S.L.; Peng, C.Y.; Huang, D.Y.; Guh, J.H.; Chen, C.C.; Shen, C.C.; Teng, C.M. Moscatilin repressed lipopolysaccharide-induced HIF- $1 \alpha$ accumulation and NF- $\kappa B$ activation in murine raw264.7 cells. Shock 2010, 33, 70-75. [CrossRef]

23. Lu, Y.; Kuang, M.; Hu, G.P.; Wu, R.B.; Wang, J.; Liu, L.; Lin, Y.C. Loddigesiinols G-J: $\alpha$-glucosidase inhibitors from Dendrobium loddigesii. Molecules 2014, 19, 8544-8555. [CrossRef]

24. Zhang, J.P.; Zheng, X.L.; Hong, J.Z.; Chen, J.C.; Zheng, Y.Y.; Xin, J.Z.; Wang, Q.Y.; Zhu, K.D.; Wang, X.N.; Shi, H. Dendrobium compound in treating 90 case of type 2 diabetes memtus. J. Fujian Univ. TCM 2011, 21, 6-10.

25. Wu, H.Z.; Xu, J.H.; Chen, L.Z.; Sun, J.J. Studies on anti-hyperglycemic effect and its mechanism of Dendrobium candidum. Chin. J. Chin. Mat. Med. 2004, 29, 160-163.

26. Gong, C.Y.; Yu, Z.Y.; Lu, B.; Yang, L.; Sheng, Y.C.; Fan, Y.M.; Ji, L.L.; Wang, Z.T. Ethanol extract of Dendrobium chrysotoxum Lindl ameliorates diabetic retinopathy and its mechanism. Vascul. Pharmacol. 2014, 62, 134-142. [CrossRef]

27. Li, C.Y.; Lu, Y.; Chen, Y.; Zheng, J.W.; Wang, J. Chemical components of Dendrobium loddigesii. Acta Sci. Nat. Univ. Sunyatseni. 2013, 52, 73-76.

28. Ito, M.; Matsuzaki, K.; Wang, J.; Daikonya, A.; Wang, N.L.; Yao, X.S.; Kitanaka, S. New phenanthrenes and stilbenes from Dendrobium loddigesii. Chem. Pharm. Bull. 2010, 58, 628-633. [CrossRef] [PubMed]

29. Li, X.W.; Chen, H.P.; He, W.B.; Yang, W.L.; Ni, F.Y.; Huang, Z.W.; Hu, H.Y.; Wang, J. Polyphenols from Dendrobium loddigesii and their biological activities. Acta Sci. Nat. Univ. Sunyatseni 2018, accepted.

30. Xu, C.J.; Wang, H.B. Research progress of Shihu Yeguang Pill. Chin. J. Chin. Ophthalmol. 2016, 4, $266-268$.

31. Lee, G.H.; Proenca, R.; Montez, J.M.; Carroll, K.M.; Darvishzadeh, J.G.; Lee, J.I.; Friedman, J.M. Abnormal splicing of the leptin receptor in diabetic mice. Nature 1996, 379, 632-635. [CrossRef] [PubMed]

32. Gu, S.; Chen, D.; Zhang, J.N.; Lv, X.; Wang, K.; Duan, L.P.; Nie, Y.; Wu, X.L. Bacterial community mapping of the mouse gastrointestinal tract. PLoS ONE 2013, 8, e74957. [CrossRef] [PubMed]

33. Garcia-Mazcorro, J.F.; Ivanov, I.; Mills, D.A.; Noratto, G. Influence of whole-wheat consumption on fecal microbial community structure of obese diabeticmice. Peer J. 2016, 4, e1702. [CrossRef] [PubMed]

34. Yang, J.; Shi, H. Research progress on Dendrobium single agent in the treatment of diabetes. Chin. Med. Mod. Dis Edu Chin. 2016, 17, 148-150.

35. Zheng, H.; Whitman, S.A.; Wu, W.; Wondrak, G.T.; Wong, P.K.; Fang, D.; Zhang, D.D. Therapeutic potential of Nrf2 activators in streptozotocin-induced diabetic nephropathy. Diabetes 2011, 60, 3055-3066. [CrossRef] [PubMed]

36. Brasnyó, P.; Molnár, G.A.; Mohás, M.; Markó, L.; Laczy, B.; Cseh, J.; Mikolás, E.; Szijártó, I.A.; Mérei, A.; Halmai, R.; et al. Resveratrol improves insulin sensitivity, reduces oxidative stress and activates the Akt pathway in type 2 diabetic patients. Br. J. Nutr. 2011, 106, 383-389. [CrossRef] [PubMed]

37. Kim, B.H.; Lee, E.S.; Choi, R.; Nawaboot, J.; Lee, M.Y.; Lee, E.Y.; Kim, H.S.; Chung, C.H. Protective effects of curcumin on renal oxidative stress and lipid metabolism in a rat model of type 2 diabetic nephropathy. Yonsei Med. J. 2016, 57, 664-673. [CrossRef] [PubMed]

38. Verdam, F.J.; Fuentes, S.; de Jonge, C.; Zoetendal, E.G.; Erbil, R.; Greve, J.W.; Buurman, W.A.; de Vos, W.M.; Rensen, S.S. Human intestinal microbiota composition is associated with local and systemic inflammation in obesity. Obesity 2013, 21, E607-E615. [CrossRef]

39. Cani, P.D.; Amar, J.; Iglesias, M.A.; Poggi, M.; Knauf, C.; Bastelica, D.; Neyrinck, A.M.; Fava, F.; Tuohy, K.M.; Chabo, C.; et al. Metabolic endotoxemia initiates obesity and insulin resistance. Diabetes 2007, 56, 1761-1772. [CrossRef] 
40. Larsen, N.; Vogensen, F.K.; van den Berg, F.W.J.; Nielsen, D.S.; Andreasen, A.S.; Pedersen, B.K.; Al-Soud, W.A.; Sørensen, S.J.; Hansen, L.H.; Jakobsen, M. Gut microbiota in human adults with type 2 diabetes differs from non-diabetic adults. PLoS ONE 2010, 5, e9085. [CrossRef]

41. Carmody, R.N.; Gerber, G.K.; Luevano, J.M., Jr.; Gatti, D.M.; Somes, L.; Svenson, K.L.; Turnbaugh, P.J. Diet dominates host genotype in shaping the murine gut microbiota. Cell. Host Microbe. 2015, 17, 72-84. [CrossRef]

42. Ley, R.E.; Bäckhed, F.; Turnbaugh, P.; Lozupone, C.A.; Knight, R.D.; Gordon, J.I. Obesity alters gut microbial ecology. Proc. Natl. Acad. Sci. USA 2005, 102, 11070-11075. [CrossRef]

43. Turnbaugh, P.J.; Ley, R.E.; Mahowald, M.A.; Magrini, V.; Mardis, E.R.; Gordon, J.I. An obesity-associated gut microbiome with increased capacity for energy harvest. Nature 2006, 444, 1027-1031. [CrossRef] [PubMed]

44. Everard, A.; Belzer, C.; Geurts, L.; Ouwerkerk, J.P.; Druart, C.; Bindels, L.B.; Guiot, Y.; Derrien, M.; Muccioli, G.G.; Delzenne, N.; et al. Cross-talk between Akkermansia muciniphila and intestinal epithelium controls diet-induced obesity. Proc. Natl. Acad Sci. USA 2013, 110, 9066-9071. [CrossRef] [PubMed]

45. Forslund, K.; Hildebrand, F.; Nielsen, T.; Falony, G.; Le Chatelier, E.; Sunagawa, S.; Prifti, E.; Vieira-Silva, S.; Gudmundsdottir, V.; Pedersen, H.; et al. Disentangling the effects of type 2 diabetes and metformin on the human gut microbiota. Nature 2015, 528, 262-266. [CrossRef] [PubMed]

46. Shin, N.R.; Lee, J.C.; Lee, H.Y.; Kim, M.S.; Whon, T.W.; Lee, M.S.; Bae, J.W. An increase in the Akkermansia spp. population induced by metformin treatment improves glucose homeostasis in diet-induced obese mice. Gut 2014, 63, 727-735. [CrossRef] [PubMed]

47. Qin, J.; Li, Y.; Cai, Z.; Li, S.; Zhu, J.; Zhang, F.; Liang, S.; Zhang, W.; Guan, Y.; Shen, D.; et al. A metagenome-wide association study of gut microbiota in type 2 diabetes. Nature 2012, 490, 55-60. [CrossRef] [PubMed]

48. LeRoith, D.; Shiloach, J.; Roth, J.; Lesniak, M.A. Insulin or a closely related molecule is native to Escherichia coli. J. Biol. Chem. 1981, 256, 6533-6536.

49. Amar, J.; Chabo, C.; Waget, A.; Klopp, P.; Vachoux, C.; Bermúdez-Humarán, L.G.; Smirnova, N.; Bergé, M.; Sulpice, T.; Lahtinen, S.; et al. Intestinal mucosal adherence and translocation of commensal bacteria at the early onset of type2 diabetes: Molecular mechanisms and probiotic treatment. EMBO Mol. Med. 2011, 3, 559-572. [CrossRef]

50. Monk, J.M.; Lepp, D.; Wu, W.; Pauls, K.P.; Robinson, L.E.; Power, K.A. Navy and black bean supplementation primes the colonic mucosal microenvironment to improve gut health. J. Nutr. Biochem. 2017, 49, 89-100. [CrossRef]

51. Suzuki, T.; Yoshida, S.; Hara, H. Physiological concentrations of short-chain fatty acids immediately suppress colonic epithelial permeability. Br. J. Nutr. 2008, 100, 297-305. [CrossRef]

52. Liao, T.; Chen, Y.P.; Huang, S.Q.; Tan, L.L.; Li, C.Q.; Huang, X.A.; Xu, Q.; Wang, Q.; Zeng, Q.P. Chondroitin sulfate elicits systemic pathogenesis in mice by interfering with gut microbiota homeostasis. BioRxiv 2017. [CrossRef]

53. Liao, T.; Chen, Y.P.; Tan, L.L.; Li, C.Q.; Wang, Q.; Huang, S.Q.; Huang, X.A.; Xu, Q.; Zeng, Q.P. Chondroitin sulfate flourishes gut sulfatase-secreting bacteria to damage mucus layers, leak bacterial debris, and trigger inflammatory lesions in mice. BioRxiv 2017. [CrossRef]

54. Sinclair, L.; Osman, O.A.; Bertilsson, S.; Eiler, A. Microbial community composition and diversity via $16 \mathrm{~S}$ rRNA gene amplicons: Evaluating the illumina platform. PLoS ONE 2015, 10, e0116955. [CrossRef] [PubMed]

55. Fadrosh, D.W.; Ma, B.; Gajer, P.; Sengamalay, N.; Ott, S.; Brotman, R.M.; Ravel, J. An improved dual-indexing approach for multiplexed 16S rRNA gene sequencing on the Illumina MiSeq platform. Microbiome 2014, 2, 6. [CrossRef] [PubMed]

56. Magoč, T.; Salzberg, S.L. FLASH: Fast length adjustment of short reads to improve genome assemblies. Bioinformatics 2011, 27, 2957-2963. [CrossRef] [PubMed]

57. Edgar, R.C. UPARSE: Highly accurate OTU sequences from microbial amplicon reads. Nat. Methods. 2013, 10, 996-998. [CrossRef] [PubMed]

58. Cole, J.R.; Wang, Q.; Fish, J.A.; Chai, B.; McGarrell, D.M.; Sun, Y.; Brown, C.T.; Porras-Alfaro, A.; Kuske, C.R.; Tiedje, J.M. Ribosomal Database Project: Data and tools for high throughput rRNA analysis. Nucl. Acid. Res. 2014, 42, D633-642. [CrossRef] [PubMed] 
59. Schloss, P.D.; Westcott, S.L.; Ryabin, T.; Hall, J.R.; Hartmann, M.; Hollister, E.B.; Lesniewski, R.A.; Oakley, B.B.; Parks, D.H.; Robinson, C.J.; Sahl, J.W.; et al. Introducing mothur: Open-source, platform-independent, community-supported software for describing and comparing microbial communities. Appl. Environ. Microbiol. 2009, 75, 7537-7541. [CrossRef]

60. White, J.R.; Nagarajan, N.; Pop, M. Statistical methods for detecting differentially abundant features in clinical metagenomic samples. PLoS Comput. Biol. 2009, 5, e1000352. [CrossRef]

61. Kanehisa, M.; Goto, S.; Kawashima, S.; Okuno, Y.; Hattori, M. The KEGG resource for deciphering the genome. Nucl. Acid. Res. 2004, 32, D277-280. [CrossRef]

62. Langille, M.G.; Zaneveld, J.; Caporaso, J.G.; McDonald, D.; Knights, D.; Reyes, J.A.; Clemente, J.C.; Burkepile, D.E.; Vega Thurber, R.L.; Knight, R.; et al. Predictive functional profiling of microbial communities using 16S rRNA marker gene sequences. Nat. Biotechnol. 2013, 31, 814-821. [CrossRef]

Sample Availability: Samples of the rich-polyphenols extract of D. Loddigesii or marker compounds (1-4) are not available from the authors.

(c) 2018 by the authors. Licensee MDPI, Basel, Switzerland. This article is an open access article distributed under the terms and conditions of the Creative Commons Attribution (CC BY) license (http://creativecommons.org/licenses/by/4.0/). 